\title{
Puppy parties and beyond: the role of early age socialization practices on adult dog behavior
}

This article was published in the following Dove Press journal:

Veterinary Medicine: Research and Reports

29 April 2015

Number of times this article has been viewed

\section{Tiffani J Howell \\ Tammie King \\ Pauleen C Bennett}

School of Psychology and Public Health, La Trobe University, Bendigo, VIC, Australia

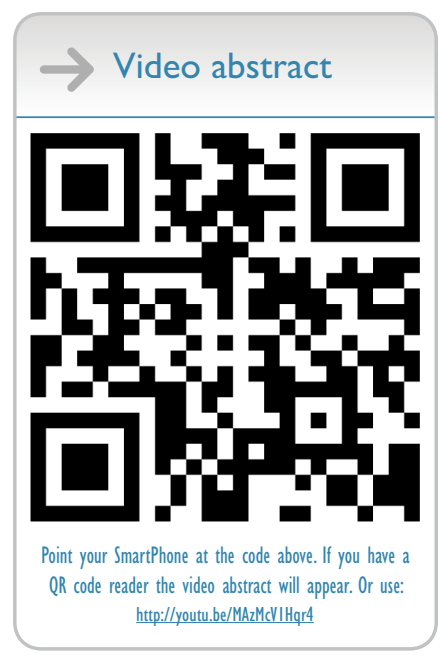

Correspondence: Tiffani J Howell School of Psychology and Public Health, La Trobe University, Box 199 , Bendigo, VIC 3552, Australia

$\mathrm{Tel}+6$ I 354447460

Fax +6I 354447850

Email t.howell@latrobe.edu.au
Abstract: The most common role of a domestic dog in the developed world currently is that of companion. Puppy socialization practices play a large role in the development of well-adjusted adult dogs that display few undesirable behaviors, and which can establish a positive, lifelong relationship with their owner. Age-appropriate socialization practices should begin within a few days of birth, and should extend well into adulthood. These practices should aim to provide exposure to many of the types of experiences, people, and objects that the dog is likely to encounter over the course of its life, in a controlled and pleasant way. Dogs that are appropriately socialized as puppies are less likely to exhibit behavioral problems as adults, including aggression and fearfulness. They are more likely to engage in positive social behaviors with humans, and can learn how to play games with humans better than dogs without proper socialization. However, the evidence in support of puppy socialization classes is less clear. There is some evidence that puppy classes positively impact adult behavior, but other studies show no clear benefit. Since socialization should begin early in a puppy's life, it is the responsibility of the breeder and the owner. Breeders can ensure that puppies are exposed to age-appropriate experiences while in the litter, and owners must ensure that the dog continues to have varied experiences throughout its life. Veterinarians are also an important part of this process, and are heavily relied upon by owners to provide information about health and behavior. Since veterinarians often see puppies during vaccinations, owners can be educated about proper socialization practices at those visits. Future research should aim to determine the minimum amounts of socialization required for a puppy, and whether there is a maximum amount, beyond which there is no benefit, or even a disadvantage.

Keywords: puppy class, aggression, dog, shelter, breeder

\section{Introduction}

Domestic dogs appear to be unique in their ability to communicate effectively with humans. ${ }^{1}$ Since they are often more attuned to human communicative cues than wolves, ${ }^{2}$ albeit with some exceptions, ${ }^{3}$ this ability likely developed during the process of domestication ${ }^{4}$ and may therefore be encoded genetically. This is important because effective communication has enabled dogs to live closely among humans for centuries, ${ }^{5}$ serving a variety of functions to benefit their owners, such as hunting, alerting to the presence of intruders, and livestock guarding and herding. ${ }^{5}$

In contemporary western societies, dogs often "work" solely to provide companionship to their owners. ${ }^{6}$ Dogs are very good at this role and have performed it well for many years, but evidence suggests that a genetic predisposition to communicate effectively with humans is not sufficient for them to be successful. The role is heavily 
dependent on the development of a successful dog-owner relationship; a failure to develop this relationship, or its subsequent breakdown, may lead to relinquishment of the dog to a shelter, a process that is distressing to owners ${ }^{7}$ and may be fatal to dogs. ${ }^{8}$ Appropriate preparation for the role of companion, in the form of early socialization, is widely considered to have long-lasting psychological benefits. ${ }^{9-12}$ Therefore, it is an important component of developing a thriving dog-owner bond.

In companion dogs, socialization typically refers to the process of desensitization, ie, gradually exposing a puppy to new experiences, animals, and objects that it is likely to encounter over the course of its life, while ensuring that the puppy finds this exposure pleasant. This process should also include exposure to numerous sounds and textures, animal species that it will likely encounter in its life, as well as humans of varying ages, sexes, and races. ${ }^{10}$ The process must begin early in the dog's life, because dogs experience a sensitive (or critical) period of socialization during this time. ${ }^{9}$ This was confirmed in a 1961 study showing that puppies that were not exposed to humans before 14 weeks of age were never able to develop normal bonds with humans later on. ${ }^{9}$

\section{Early periods of a dog's life}

A puppy experiences three key periods in its social development, ie, the primary period, the socialization period, and the enrichment ${ }^{10}$ or juvenile ${ }^{12}$ period. Although the name of the second period is the "socialization" period, all three periods are relevant to the process of socialization in the commonly used sense of the word.

The primary period, which is a combination of the neonatal and transition periods, ${ }^{12}$ lasts from birth until the puppy is approximately 3 weeks of age..$^{10}$ During this time, their sensory capabilities are not yet fully developed, so they are wholly reliant on their mother's care. They gradually become more aware of their surroundings over the course of the period, as their eyes and ears become functional, but, for much of the time, they rely largely on their sense of touch to navigate the world. ${ }^{10,12}$ Not surprisingly, therefore, there is evidence to suggest that various tactile experiences during this time can affect later behavior. For instance, in one study, puppies that were handled gently every day early in their lives behaved more calmly at 8 weeks of age than puppies that were not handled. ${ }^{13}$ In addition to handling, this study also compared dogs raised in home settings or in a professional breeding kennel. They concluded that while all puppies may benefit from gentle handling early in life, this process is particularly helpful for puppies living in an environment with limited enrichment, such as professional breeding kennels. ${ }^{13}$ Despite limitations in their ability to see and hear, it is clear that puppies at this age receive long-term benefits from appropriate handling encounters with humans.

Early stimulation methods that produce mild stress through handling of puppies during the first 10 days of their life have also been shown to have positive results. ${ }^{10}$ According to one study, puppies exposed to early stimulation were more resilient to stress as adults, experiencing physiological benefits such as improved cardiovascular, adrenal, and immune function, when compared with puppies that were not gently handled during this early period of their lives. ${ }^{10}$

Toward the end of the primary period, the mother gradually stops providing constant care to the puppies, and the puppies begin to focus more on developing social relationships with their littermates. ${ }^{12}$ This leads into the socialization period of development, which occurs from approximately 3 until 12 weeks of age, ${ }^{12,14}$ and certainly no later than 14 weeks of age. ${ }^{9}$ This period includes the beginning of play between littermates, following each other and running in groups. ${ }^{10,12}$ This has important implications, especially for puppies that are born without littermates and suggests particular care is required when raising lone puppies. Fear responses also develop during this period; Scott and Fuller reported that puppies at 5 weeks of age show a strong fear response toward all loud noises and unfamiliar environments, but over time they learn which stimuli represent danger and which are harmless. ${ }^{12,15,16}$

Puppies show fear toward humans early in this period, but this rapidly disappears with regular positive human contact. ${ }^{12}$ Among puppies that do not have exposure to humans, the fear response can become permanent; puppies without exposure to humans before the age of 14 weeks are unable to form normal relationships with humans. ${ }^{9,16}$ During the course of the socialization period, puppies become less fearful of unfamiliar environments ${ }^{15}$ and demonstrate increased approach behaviors toward humans and other objects, provided that they have been exposed to humans and new experiences beginning early in this period. ${ }^{12}$

The socialization period is crucial for the development and maintenance of long-term relationships with humans; however, the process of socialization should not end at 12 or 14 weeks of age. The third period of development, the enrichment or juvenile period, is often considered to last until sexual maturity, although, in dogs, this is not the same time as behavioral maturity occurs. ${ }^{14}$ It has not been studied as heavily as the socialization period, ${ }^{14}$ but it is an important period for exposing a dog to many of the experiences that it will likely encounter over the rest of its life. ${ }^{10}$ 
By the juvenile period, puppies in developed countries will usually have received sufficient vaccinations to be able to go virtually anywhere their owner goes without risking their health through exposure to the most common communicable diseases..$^{17}$ They will have also started to develop an understanding of the difference between safe and dangerous stimuli, so they do not show the strong indiscriminate fear responses that characterize the early socialization period. ${ }^{12}$ Provided that they have received appropriate, positive socialization experiences during the previous periods, they are presumably less stressed by unfamiliar stimuli, and can cope with exposure to novel situations and experiences. Indeed, new encounters during this period may have long-term beneficial effects on behavior, including increased interactions with humans and calm behavior. ${ }^{18,19}$

Dog welfare ${ }^{20}$ and breeding ${ }^{21}$ organizations recommend engaging in socialization practices with puppies; this includes exposure to objects, people, animals, and places outside the home during both the socialization period and early in the juvenile period. This is consistent with the limited evidence available, which confirms that the process of socialization does not end when the socialization period officially ends, but continues well into the juvenile period and into adulthood.

\section{Socialization effects on adult dog behavior}

The current literature and common consensus among dog behavior experts is that lack of appropriate socialization during the sensitive period, along with lack of appropriate ongoing socialization during the dog's life, plays a large role in whether or not the dog develops behavioral problems. ${ }^{11,14,22,23}$ Lack of appropriate early socialization to a range of people and other animals, as well as different environments, can result in adult dogs that exhibit problematic behaviors, such as undesirable aggression and fearfulness. ${ }^{10,11,24}$ Lack of exposure to animals that will be forming part of the puppy's social group as an adult, which may include other dogs, different animal species, and people and children, can result in an individual that is unable to form strong social bonds with these groups. ${ }^{12}$

In one study, social and environmental exposure administered to puppies was found to be positively correlated with measures of sociability, and negatively correlated with measures of fear and aggression. ${ }^{25}$ Socialization with other animal species was negatively associated with inappropriate predatory behavior, and dogs that attended puppy preschool were found to be less fearful, less aggressive, and more social..$^{25}$ Another study, however, highlights the importance of appropriate types of socialization: adult dogs with a fear of noises, such as thunder and fireworks, were more likely to have experienced thunder when they were younger than 4 months of age. ${ }^{26}$ This evidence indicates that early experiences play an important part in shaping behavior. If done in an appropriate manner, these experiences will help to reduce the likelihood of problematic behavior occurring in future. However, if this process is not well controlled, it could result in an increased likelihood of undesirable adult behavior.

A 1999 study examined the effects of socialization on the ability to play search games with humans, an important element of search and rescue dog training. ${ }^{27}$ Dogs that had not been exposed to humans before they were 1 year of age could never learn how to play a searching game, while pet dogs with human exposure were able to learn how to play. However, one of the human-deprived dogs had lived with humans until it was 4 months old before being removed from the human environment, and it performed better than the other human-deprived dogs in this study. ${ }^{27}$ While the performance of a single dog should not lead to generalizations, this study demonstrates the positive long-term effects of early socialization to humans, possibly even if a dog is later removed from human environments for an extended period of time.

A study conducted by Appleby et al investigated whether there was a relationship between the display of aggressive and avoidance behavior and dogs' experiences during the first 6 months of their life. ${ }^{24}$ Their results indicated significant differences in aggression toward unfamiliar people and avoidance behavior between dogs who were raised in kennels, a barn, or a shed, compared with a domestic setting (ie, in the breeder's home). This result points to the importance of environment in the socialization process. Breeders who raise a litter of puppies in a kennel, barn, or shed should be able to provide adequate socialization to the puppies; however, they may have to make a special effort to ensure that these experiences occur.

The relationship between socialization practice and the prevalence of undesirable behaviors in adult dogs is important not just because these behaviors are annoying to owners. Undesirable behaviors may also signal the presence of other underlying issues that may impact negatively on the welfare of the dog. They may result from an underlying physical health problem, for example, or confusion about what behaviors are expected by the owner, and/or poor mental health in the $\operatorname{dog} .{ }^{28}$ This can become a vicious cycle; a poorly socialized dog does not understand what its owner expects and may receive conflicting or confusing messages from the 
owner, which causes it to become stressed, resulting in more undesirable behavior. If the owner does not then make his/her expectations for the dog known in a very clear way or lower these expectations in accordance with the dog's ability to meet them, then this stress continues, causing even further undesirable behavior. ${ }^{28}$ It is important that owners and veterinarians take behavioral problems seriously; regardless of whether or not they escalate to the point where the owner considers relinquishing the dog to a shelter, the dog's welfare may be compromised if it is displaying problematic behaviors.

There are breed differences in the development of stimulus response, according to Scott and Fuller's seminal work in the 1960s. ${ }^{12}$ For example, a larger percentage of Fox terriers and Beagles had developed a startle response at 3 weeks of age than Cocker spaniels and Shetland Sheepdogs. However, by 4 weeks, all dogs of all breeds studied had developed the startle response. Furthermore, Coppinger and Coppinger state that different socialization experiences will have varying effects on certain dog breeds. ${ }^{29}$ They exposed a Labrador retriever puppy to livestock, in order to determine whether it would be possible to turn her into a livestock guarding dog. Unlike a dog that is bred specifically for that purpose, the Labrador never showed intense protective behaviors toward the livestock. ${ }^{29}$ Therefore, it is likely that breeding specifically for certain traits does influence ideal socialization practices and amounts.

Perhaps there are sex differences in socialization practice needs, based on adult behavioral outcomes. Male dogs are more likely to be rated by authorities as expressing dominant and aggressive behaviors, and female dogs are more likely to be perceived as more obedient, easier to housetrain, and more demanding of affection. ${ }^{30}$ However, to our knowledge, sex differences in socialization have not been examined, even though Scott and Fuller did explain that, at any given moment in a dog's development, males are likely to be physically larger than females, and size does affect behavior. ${ }^{12,31}$ They also state, however, that growth curve differences between the sexes do not necessarily correlate with differences in the rate of learning, so it is possible that there is no discernible sex difference in socialization needs.

The results of available studies provide strong evidence of a link between inadequate socialization during puppyhood and undesirable adult dog behaviors. What they do not explain, however, is how much socialization is optimal. Having no socialization has very clear negative impacts, so there must be a minimum amount required, but how much this actually consists of is not known. Also unknown is whether there is a maximum amount of socialization required, beyond which any extra socialization is unnecessary or even detrimental.

These studies also do not explain why there is a link between puppy socialization and adult behavior. One possible reason is that the socialization periods during puppyhood are like biological windows that open and close at certain times, and an animal that does not have necessary experiences during those windows misses the opportunity forever. ${ }^{12,16,29}$ More likely is that there are periods where a puppy is developmentally more sensitive/receptive to certain experiences, and that learning plays a critical role in this process. Animals can only learn about things to which they are introduced, and they may do so more readily during a sensitive period. Therefore, a lack of exposure to a particular object or type of animal at the correct developmental time necessarily means that dogs do not have the chance to learn, or take longer to learn, whether that object or animal is harmless or dangerous. ${ }^{14}$ In addition, since mild stress seems to be an integral part of the socialization and exposure process, ${ }^{10,13}$ a lack of mild desensitization-related stress early in life may have negative neurological effects on the dog and make it incapable of handling any amount of stress later in life. ${ }^{32}$ Most likely, a combination of learning via desensitization and stress inoculation acts to prevent the behavioral problems noted in adult dogs without adequate socialization experiences.

\section{Do puppy classes make a difference? The jury is still out}

Despite the general agreement that puppy socialization practices are crucial in the development of normal social relationships and psychological health in adult dogs, the evidence is less clear on the benefit of puppy classes specifically. Many studies about the effects of puppy classes on adult dog behavior have been epidemiological in nature, meaning that they correlate the behavior of adult dogs with various demographic, owner, and environmental factors. This method is useful in establishing which factors have a stronger predictive value on the outcome, but there is some debate as to whether they can truly determine causal relationships. ${ }^{33}$ This can limit their utility in evaluating whether a single factor, such as attendance at a puppy class, has a clear effect on adult dog behavior. Nonetheless, because controlled experimental studies on specific populations of puppies are rare, epidemiological studies are probably the best available alternative in understanding whether there is any relationship between puppy classes and adult dog behavior.

In one such study, Duxbury et al found that puppies who were handled frequently and attended socialization classes, 
were less likely to be surrendered to a shelter as adults. ${ }^{34}$ However, some of the other factors that predicted retention in the home were having a female owner, sleeping near the owner's bed, responsiveness to commands, and having no young children in the home. Therefore, it is possible that puppy socialization classes are one aspect of a suite of owner factors that reduce the likelihood of relinquishment.

Another study showed that attendance at puppy classes reduced the risk of aggression toward unfamiliar people. ${ }^{35}$ As with the study by Duxbury et al, there were many other factors predicting less aggressive behavior, including being a desexed female, having a female owner, attending ringcraft classes, and positive reinforcement training methods. ${ }^{35}$ A further study showed a similar result: attendance at puppy socialization classes was associated with improved positive social behaviors, and fewer behavioral problems, as adults. ${ }^{25}$ Other factors that predicted these outcomes were being a male dog, a higher level of environmental and social interactions overall, and remaining in the litter longer.

Taken together, the results of these studies suggest that socialization classes are one piece of the puzzle in developing adult dog behavior. Since these studies sometimes show contradictory results (eg, male dogs showed fewer behavioral problems in one study ${ }^{25}$ and desexed females showed less aggression in another ${ }^{35}$ ), it is possible that the samples, or unaccounted for variables, have affected the results of these epidemiological studies.

Indeed, one study that examined the effectiveness of puppy socialization programs suggested that exposure to regular handling procedures and novel stimuli did not significantly improve responses compared to puppies which did not have these types of experiences. ${ }^{36}$ However, puppies that received training performed better when given obedience commands compared with groups that did not. ${ }^{36}$ The authors suggest that, for puppies living in typical human homes, the stimuli and experiences to which they are exposed on a daily basis in the home may be enough to provide them with adequate socialization. Therefore, an additional class may not impart a clear benefit. This was supported by the results of another study, which showed that training and/or socialization classes provided in addition to the typical training that puppies in the guide dog program receive do not affect guide dog success rates. ${ }^{37}$

Another reason why puppy socialization classes do not always appear to singularly affect adult dog behavior could relate to the ways in which some classes are run. In most countries, there are no accreditation procedures in place and puppy classes may be run by people who lack the skills or experience necessary for this purpose. Perhaps many puppies simply find the experience too stressful to receive a noticeable benefit. Although mild stress is a component of socialization, it is important not to stress puppies too much, or else the benefits will not be conferred..$^{10,13}$

This level of stress would most likely be impacted by how the classes are delivered, who is teaching them, and what the class curriculum involves. A poorly run class, which delivers suboptimal advice to dog owners, is not going to be beneficial in enhancing the human-canine bond and may result in behavioral problems during puppy development. A study on puppy class trainer "dogmanship", ie, a trainer's ability to effectively read and respond to dog communicative cues, ${ }^{38}$ would be useful in determining the extent to which trainer quality impacts the levels of stress experienced by puppies in class and/or socialization class outcomes.

There was some evidence of the role of stress on puppy class outcomes in a study that examined the effect of dogappeasing pheromone (DAP) on puppy behaviors before, during, and after puppy class. ${ }^{39}$ In this randomized, doubleblind, controlled clinical trial, puppies attended an 8-week puppy class with either a DAP collar or a placebo collar. The results showed that, compared with dogs wearing a placebo collar, dogs with a DAP collar were less fearful, and engaged in longer and more positive interactions with other puppies during class. Based on owner reports 12 months after the classes ended, they were also better socialized and more adaptable to unfamiliar situations..$^{39}$ This study was not epidemiological in nature, ie, looking retrospectively to find trends, but was a randomized, controlled experimental trial which may suggest a causal relationship between DAP collars and desirable behaviors. Therefore, these results should be taken into serious consideration during puppy socialization course design. It is possible that use of a DAP collar mediates the way that the puppy classes are run, and would permit novice dog trainers to help socialize puppies adequately in this way. Further research examining the benefits of DAP collars, as well as the effectiveness of individual trainers in puppy classes, should be undertaken.

In sum, the results of these studies do not provide strong evidence for the benefit, or lack thereof, of puppy classes on adult dog behavior. More research is needed to determine whether puppies need a socialization class on top of the typical socialization practices that they are receiving from their owners. These results do, however, raise interesting questions. Perhaps more socialization is not better, or even necessary. It is possible that there is a tipping point at which a puppy has been adequately socialized, and any additional 
socialization practices simply do not make any difference. Future studies should aim to understand whether such a tipping point exists, or whether there are several tipping points in different developmental periods of a dog's life. Dog behavior experts often recommend an ongoing process of socialization and enrichment. ${ }^{22,23}$ This recommendation is likely sensible, but at present it is based on practical experience rather than empirical evidence, since there is no clear evidence to speak of regarding the amount and length of time that is necessary to adequately socialize a dog.

Most likely due to ethical issues in scientific research, there appears to be a considerable lack of current scientific studies that have evaluated in detail the effects of social deprivation on puppies during their periods of development. ${ }^{40}$ Current studies often examine normal levels compared with enriched levels of socialization. ${ }^{36,37}$ Furthermore, the studies that have examined this effect in dogs and other animal species are often conducted within a laboratory environment. ${ }^{18,19}$ Most dogs in western societies are kept as companions and live closely with humans. ${ }^{41}$ Therefore, there are limitations to take into account when evaluating socialization practices and attempting to infer which levels administered in puppyhood are detrimental or advantageous to future adult behavior.

\section{Adjusting owner expectations for dogs in the modern world}

There has been one study showing a negative correlation between puppy socialization classes and relinquishment to a shelter, along with other factors such as having a female owner and responsiveness to commands. ${ }^{34}$ Otherwise, there does not appear to be any direct connection between puppy socialization practice and retention in the home, most likely because it has not been thoroughly tested. This is surprising since inadequate puppy socialization relates to undesirable adult dog behavior, which is a common reason for relinquishment to a shelter. ${ }^{8,42,43}$ Therefore, it is possible that there is a strong, indirect connection between socialization and retention, even if studies demonstrating this effect are lacking.

Indeed, engaging in appropriate socialization and training practices may be even more critical in the modern era than previously. Caring for a dog can be challenging, especially when they exhibit unacceptable behaviors, and our expectations regarding appropriate dog behavior sometimes appear unrealistic. ${ }^{44}$ For example, it is now common for many companion dogs to be left alone for extended periods, expected to behave calmly and quietly, with little social contact. ${ }^{45}$ Owners are the ultimate determinants of whether their dog's behavior is problematic or acceptable. What would constitute a normal level of barking by one owner may be perceived as excessive by another. Some owners may have poor knowledge of which dog behaviors are species-appropriate and which are excessive and/or indicative of a possible health problem; they may not provide adequate socialization practices and may lack understanding of the basic principles of behavior modification. These owners are often unable to train their dogs effectively or provide their dogs with adequate mental and physical stimulation, and they are more likely to have dogs with behavioral problems. ${ }^{28}$

Dogs that behave in a manner considered to be unacceptable can be a source of resentment and unpleasantness, not only to their owners, but also to the general community, as evidenced by legal regulations aimed at controlling dog behavior. ${ }^{46,47}$ Barking, destruction of property, causing traffic hazards by roaming on roads, and posing threats to livestock, wildlife, and humans all impact on community wellbeing and draw heavily on public resources. Undesirable behaviors may result in the relinquishment of a dog to an animal shelter, ${ }^{8,43,48}$ and approximately $30 \%$ of dogs who enter shelters are euthanized, ${ }^{7}$ with kill rates as high as $68 \%$ reported in some shelters. ${ }^{49}$ This is a welfare concern and highlights the importance of establishing why there is a high prevalence of relinquishment of dogs, and determining ways in which owners can maintain positive bonds with their dogs for the lifetime of the animals.

It is important to educate breeders and owners, as well as those providing advice on dog behavior, to ensure the most up to date information is being disseminated and implemented. Dog owners may lack appropriate knowledge regarding dog socialization practices and canine behavior, as well as what constitute a dog's basic needs. Additionally, owners may lack sufficient skills and knowledge relating to canine social communication, psychological learning theory, and appropriate behavior modification techniques. It is unclear exactly where owners seek information regarding dog behavior; they may be obtaining suitable information and not implementing it, or acquiring substandard information from a variety of unreliable sources.

\section{Roles of veterinarian, breeder, and owner in providing early and lifelong socialization opportunities}

Puppies are generally acquired by their new owners when aged 8-12 weeks. Up until this age, it is the responsibility of the breeder to ensure puppies in their care have undergone early stimulation practice ${ }^{10}$ and have been adequately socialized for the environment in which they will be spending 
most of their lives, as well as being conditioned for the main role they will be undertaking. Considering that most dogs are kept as pets, ${ }^{41}$ it is important that these dogs are raised in a manner that ensures they adapt easily to this particular lifestyle. This means that the breeder has a responsibility to select breeding stock capable of producing companion dogs, as well as a responsibility to evaluate puppies and match owners with appropriate puppies. Puppy temperament tests have produced mixed results. ${ }^{50}$ For example, one study showed no significant relationship between puppy behavior and successful completion of a service dog program. ${ }^{51}$ Another study, however, showed that fearfulness in 8-week-old puppies predicted fearfulness as adults, and this predictive capability continued to improve with age. ${ }^{52}$ In the same study, willingness to play with a ball as a puppy negatively correlated with adult fearfulness. While puppy tests may not always provide an accurate measure of adult dog behavior, they do illustrate that temperament traits vary between individuals from puppyhood, and these may sometimes provide a "best guess" regarding future behavior. Breeders can use this knowledge to ensure that owners and puppies are appropriately matched.

Once puppies leave the breeder, it is the responsibility of the owner to ensure the dog becomes a well-socialized individual. The owner is therefore required to spend considerable time socializing their dog appropriately, but dogs do not always receive the necessary socialization and training protocols, and as a result behavioral problems may develop. ${ }^{11}$ Similarly, owners may have unrealistic expectations of dog behavior. A survey of the Australian public indicated that the majority of people consider an "ideal" dog to be one that is friendly, fully housetrained, safe with children, affectionate, obedient, and does not escape the property. ${ }^{53}$ Interestingly, respondents rated "fully housetrained" and "obedient" highly but did not rate "trainable" as an equally desirable characteristic, suggesting a lack of knowledge regarding animal behavior and unrealistic expectations that dogs should be readily obedient regardless of their trainability. Adequate socialization practices, whereby dogs are exposed in a positive manner to a range of sights, sounds, smells, textures, places, people, and animals, is likely to produce well-adjusted individuals that can handle future exposure to novelty and have strong positive social relationships.

A recent UK workshop conducted by experts on companion dog welfare recommended that inappropriate husbandry, lack of owner knowledge, undesirable behaviors, and inappropriate socialization are welfare problems of strategic priority for resource investment to improve companion dog welfare. ${ }^{54}$ The Royal Society for the Prevention of Cruelty to Animals and local government sectors actively promote responsible pet ownership and education relating to acquisition of dogs, socialization, and pet dog training in Australia. ${ }^{20}$ However, somehow the information is failing to reach many owners or they are not implementing it. This is made apparent by the large number of dogs that are relinquished to shelters due to behavioral problems..$^{8,42,43,48}$ It is possible that these behavioral problems developed in spite of adequate socialization practices during puppyhood in some cases. Given the strong relationship between socialization and adult behavior, it is likely that inadequate puppy socialization was at least somewhat responsible for these behavioral problems in most cases.

The role of the breeder is not only to raise healthy and sociable puppies, but also to appropriately select and educate potential owners about the importance of appropriate ongoing socialization and training for companion dogs. Similarly, the role of veterinary professionals is of vital importance in providing accurate information regarding dog socialization and behavior. ${ }^{40}$ Often veterinarians and veterinary nurses are the first point of contact for a client after acquisition of a puppy for general advice, health checks, and vaccinations. Furthermore, many veterinarians are regularly meeting owners with puppies at the development periods where good socialization practices need to occur. ${ }^{17}$ These practices are critical in shaping future behavior, and it is necessary that they are conducted in an appropriate manner. ${ }^{55} \mathrm{~A}$ recent survey indicated that approximately $75 \%$ of dog owners consider veterinarians to be a valuable source of information on petrelated issues. Furthermore, over half of all owners indicated that veterinarians are the best source of information. ${ }^{56}$

This last result is important, but it is also of some concern, since theoretical and practical knowledge relating to dog behavior and welfare are not core components of many veterinary science ${ }^{57}$ or animal science curricula. ${ }^{58}$ Given that behavioral problems are a leading cause for pet relinquishment, the veterinary profession needs to be able to provide appropriate advice relating to behavior and socialization, as well as preventive health care. Many veterinarians undoubtedly have an intuitive understanding of best management practice for dog behavior and socialization based on their experience in veterinary practice, and can therefore provide their clients with sound advice. Others choose to become experts in behavior by undertaking additional study. However, behavior management courses should be included in all veterinary science curricula in order to better standardize the advice provided by veterinarians to clients who need 
their help. This will improve the likelihood that owners who attend virtually any veterinary clinic will receive appropriate information about behavior, based on the current state of the science. Otherwise, the profession may need to acknowledge this lack of behavioral education and implement policies to refer owners who have behavioral concerns about their dogs to suitably qualified trainers and/or veterinary behaviorists.

A clinic with a veterinary behaviorist would be able to provide a "one stop shop" for dog owners who are experiencing concerns about their dog's behavior. The veterinarians could ensure that there is no underlying physical problem, and refer the owner to the veterinary behaviorist for tailored advice on solving the behavioral problem. Many veterinarians are undoubtedly qualified to provide advice on most behavioral problems. However, for the more uncommon problems, or problems that are particularly difficult to resolve using typical techniques, a veterinary behaviorist may prove a valuable resource.

The prevalence of dog behavior problems, coupled with irresponsible or poorly informed dog breeder practices, the sourcing of potentially unreliable information, and lack of owner knowledge, contribute to poor companion dog welfare. Indeed, according to the results of one recent survey, many dog owners believe that their dogs are cognitively capable of more than what has been demonstrated in empirical research studies. ${ }^{59}$ This may affect the dog-owner relationship if owners believe that a dog is being "dominant" or "knows better", when the dog exhibits an undesirable behavior because it does not understand the owner's expectations.

New research is needed in order to build on existing scientific findings, which will help determine best breeding and handling practices, factors underlying owner knowledge, and where such information is sourced. This information will allow groups such as welfare organizations and local government to develop and target their educational campaigns, to ensure that the community is equipped with the best information to optimize companion dog welfare. Best practice protocols regarding puppy handling and socialization can be implemented by breeders. If owners are sourcing information predominantly from veterinarians and veterinary nurses, it is necessary to establish whether this is credible advice and ensure these professionals are up to date with best-practice methods in dog behavior, training, and socialization.

\section{Recommendations for future research and practice}

To conclude, the existing scientific evidence suggests that socialization is a key component of producing an adult dog which behaves in an appropriate manner and is well-suited to living with humans in modern day society. Puppies should ideally be exposed to very mild stressors during the neonatal period, and must receive regular human contact, of an appropriate kind, during the socialization period. This information is particularly important for breeders, given that puppies are generally still in the litter during these periods. From the socialization period and throughout the juvenile or enrichment period, owners should take care to expose puppies safely to a wide variety of different experiences, objects, animals, and people, while ensuring that the puppy enjoys these experiences and is not overly frightened by them. All of these practices will help improve the likelihood of raising a temperamentally sound dog.

The benefits of puppy socialization classes are less clear than the beneficial effects of socialization in general. It is possible that most pet dogs are raised in enriching environments that provide adequate socialization without the need for special classes. Since the results of these studies have been mixed, future research should aim to determine whether there is a clear benefit to attending puppy classes. This could be included in research studies aiming to establish best practice models for early handling and socialization from puppyhood into adulthood.

Studies examining the benefits of appropriately run puppy socialization classes held in veterinary clinics would be useful in helping researchers understand whether this process effectively socializes puppies to the clinic. These classes potentially reduce fearful responses created in animals which only ever come to the clinic when they are hurt and scared. Puppy classes may also be useful in terms of building a relationship with future clients and educating new owners, thereby encouraging retention of clients who regularly bring their dog into the clinic for health and behavioral advice. Therefore, veterinary clinic puppy socialization classes might be helpful for reasons beyond socialization itself.

While there is general agreement about the importance of socialization, it is unclear just how much socialization is actually necessary. Perhaps the minimum required varies from individual to individual, or maybe there are breed differences. Is there a maximum amount? If so, is more still better, or is it worse, or does it make no difference at all? Perhaps there are interaction effects as well, so that a puppy with extensive socialization to humans but little experience with other animals will have different behavioral outcomes as an adult than a puppy with equal, but moderate, levels of experience with humans and other animals. Despite the extensive work undertaken by canine scientists to evaluate the 
effects of socialization, there is still much to be done before researchers can develop a comprehensive understanding of the process.

Research should also attempt to understand the level of breeder knowledge about dog behavior and socialization. It is fair to assume that a breeder who is educated about the importance of socialization would make every effort to ensure that their puppies are well socialized. However, the current level of breeder knowledge is not known; it is possible that a more knowledgeable breeder will produce puppies with solid temperaments, but this should be explored in depth. If it is indeed the case, then breeders should be encouraged to attend seminars and workshops designed to increase their knowledge about the role of socialization in adult dog behavior. Much relevant information is already provided on purebred club websites, such as the American Kennel Club and the United Kingdom Kennel Club. ${ }^{60,61}$

Just as breeder understanding of socialization is unknown, research has not established owner knowledge of dog behavior, training, socialization, behavior modification, and learning theory. As with breeders, it is possible that owners who are educated on these topics will raise well-adjusted dogs that exhibit few undesirable behaviors. Researchers should aim to determine whether this is in fact the case. It is also possible that owners who are educated about dog behavior will be less likely to interpret normal $\operatorname{dog}^{51}$ behavior as abnormal or excessive, but this has not been confirmed in scientific studies.

Finally, since many veterinary science programs do not require the completion of $\mathrm{dog}$ behavior courses, it is important to understand the level of knowledge of veterinary professionals regarding dog behavior and behavior modification. This will help identify gaps in that knowledge, which can be rectified by including dog behavior components in future degree programs, and by offering professional development programs on socialization for current veterinarians. Since the veterinarian is often the first port of call for new owners, or owners who are concerned about their dog's behavior, this knowledge could potentially impact the lives of thousands of animals.

It is clear that both dogs and owners benefit from a strong dog-owner bond. Socialization is a crucial element in the development of a positive relationship between dog and owner. This process, which begins early in a dog's life, has long-term and wide-ranging effects on the adult behavior of the dog. A well-socialized dog will likely display fewer undesirable behaviors as an adult, which is a common reason why the dog-owner bond breaks down and dogs are relinquished to shelters. It is unclear just how much socialization is necessary to produce a well-adjusted adult dog, but appropriate socialization practice as a puppy provides the dog with a strong foundation for a long, healthy life with a devoted owner.

\section{Disclosure}

The authors report no conflicts of interest in this work.

\section{References}

1. Reid PJ. Adapting to the human world: dogs' responsiveness to our social cues. Behav Processes. 2009;80:325-333.

2. Viranyi Z, Gacsi M, Kubinyi E, et al. Comprehension of human pointing gestures in young human-reared wolves (Canis lupus) and dogs (Canis familiaris). Anim Cogn. 2008;11:373-387.

3. Gacsi M, Gyori B, Viranyi Z, et al. Explaining dog wolf differences in utilizing human pointing gestures: selection for synergistic shifts in the development of some social skills. PLoS One. 2009;4:E6584.

4. Hare B, Brown M, Williamson C, Tomasello M. The domestication of social cognition in dogs. Science. 2002;298:1634-1636.

5. Clutton-Brock J. Origins of the dog: domestication and early history. In: Serpell J, editor. The Domestic Dog: Its Evolution, Behaviour, and Interactions with People. Cambridge, UK: Cambridge University Press; 1995.

6. Bennett P, Rohlf V. Owner-companion dog interactions: relationships between demographic variables, potentially problematic behaviours, training engagement and shared activities. Appl Anim Behav Sci. 2007; 102:65-84.

7. Marston LC, Bennett PC. Reforging the bond - towards successful canine adoption. Appl Anim Behav Sci. 2003;83:227-245.

8. Marston LC, Bennett P, Coleman G. What happens to shelter dogs? An analysis of data for 1 year from three Australian shelters. J Appl Anim Welf Sci. 2004; 7:27-47.

9. Freedman DG, King JA, Elliott O. Critical period in the social development of dogs. Science. 1961;133:1016-1017.

10. Battaglia CL. Periods of early development and the effects of stimulation and social experiences in the canine. J Vet Behav. 2009;4:203-210.

11. Serpell J, Jagoe JA. Early experience and the development of behaviour. In: Serpell J, editor. The Domestic Dog: Its Evolution, Behaviour, and Interactions with People. Cambridge, UK: Cambridge University Press; 1995.

12. Scott JP, Fuller JL. Genetics and Social Behavior of the Dog. Chicago, IL, USA: University of Chicago Press; 1965.

13. Gazzano A, Mariti C, Notari L, Sighieri C, McBride EA. Effects of early gentling and early environment on emotional development of puppies. Appl Anim Behav Sci. 2008;110:294-304.

14. Miklosi A. Dog Behaviour, Evolution, and Cognition. 1st ed. New York, NY, USA: Oxford University Press; 2008.

15. Elliott O, Scott JP. The development of emotional distress reactions to separation, in puppies. J Genet Psychol. 1961;99:3-22.

16. Scott JP. The process of primary socialization in canine and human infants. Monogr Soc Res Child Dev. 1963;28:1-47.

17. Klingborg DJ, Hustead DR, Curry-Galvin EA, et al. AVMA Council on Biologic and Therapeutic Agents' report on cat and dog vaccines. J Am Vet Med Assoc. 2002;221:1401-1407.

18. Hubrecht RC. Enrichment in puppyhood and its effects on later behavior of dogs. Lab Anim Sci. 1995;45:70-75.

19. Boxall J, Heath S, Bate S, Brautigam J. Modern concepts of socialisation for dogs: implications for their behaviour, welfare and use in scientific procedures. Altern Lab Anim. 2004;32:81-93.

20. Royal Society for the Prevention of Cruelty to Animals Australia. Is socialising my puppy important? Knowledge Base, 2013. Available from: http://kb.rspca.org.au/Is-socialising-my-puppy-important_302. html. Accessed January 16, 2015. 
21. The Kennel Club. Puppy socialisation. Getting a dog, 2014. Available from: http://www.thekennelclub.org.uk/getting-a-dog-or-puppy/generaladvice-about-caring-for-your-new-puppy-or-dog/puppy-socialisation/. Accessed January 16, 2015.

22. Donaldson J. The Culture Clash. Berkeley, CA, USA: James and Kenneth Publishers; 1996.

23. Donaldson J. Oh Behave! Dogs from Pavlov to Premack to Pinker. Wenatchee, WA, USA: Dogwise Publishing; 2008.

24. Appleby DL, Bradshaw JWS, Casey RA. Relationship between aggressive and avoidance behaviour by dogs and their experience in the first six months of life. Vet Rec. 2002;150:434-438.

25. Ward MR. Behavioural Therapy Success and the Effect of Socialisation on Subsequent Behaviour in Dogs. Palmerston North, New Zealand: Veterinary Science, Massey University; 2003.

26. Blackwell EJ, Bradshaw JWS, Casey RA. Fear responses to noises in domestic dogs: prevalence, risk factors and co-occurrence with other fear related behaviour. Appl Anim Behav Sci. 2013;145:15-25.

27. Balevičiūtė G. Effect of a human contact and object-oriented play exercises on the development of behaviour features, favourable for search training, of the domestic dog (Canis familiaris). Acta Zool Lit. 1999;9:27-34.

28. Landsberg GM, Hunthausen WL, Ackerman LJ. Behavior Problems of the Dog and Cat. 3rd ed. London, UK: Saunders Elsevier Health Sciences; 2012.

29. Coppinger R, Coppinger L. Dogs: A New Understanding of Canine Origin, Behavior, and Evolution. Chicago, IL, USA: University of Chicago Press; 2002.

30. Hart BL. Analysing breed and gender differences in behaviour. In: Serpell J, editor. The Domestic Dog: Its Evolution, Behaviour, and Interactions with People. Cambridge, UK: Cambridge University Press; 1995.

31. Svobodová I, Vápeník P, Pinc L, Bartoš L. Testing German shepherd puppies to assess their chances of certification. Appl Anim Behav Sci. 2008;113:139-149.

32. Fox MW, Stelzner D. Behavioural effects of differential early experience in the dog. Anim Behav. 1966;14:273-281.

33. Rothman K, Greenland S. Causation and causal inference in epidemiology. Am J Public Health. 2005;95(S1):S144-S150.

34. Duxbury MM, Jackson JA, Line SW, Anderson RK. Evaluation of association between retention in the home and attendance at puppy socialization classes. J Am Vet Med Assoc. 2003;223:61-66.

35. Casey RA, Loftus B, Bolster C, Richards GJ, Blackwell EJ. Human directed aggression in domestic dogs (Canis familiaris): occurrence in different contexts and risk factors. Appl Anim Behav Sci. 2014;152: $52-63$

36. Seksel K, Mazurski EJ, Taylor A. Puppy socialisation programs: short and long term behavioural effects. Appl Anim Behav Sci. 1999;62:335-349.

37. Batt L, Batt M, Baguley J, McGreevy P. The effects of structured sessions for juvenile training and socialization on guide dog success and puppy-raiser participation. J Vet Behav. 2008;3:199-206.

38. Payne E, Bennett P, McGreevy P. Current perspectives on attachment and bonding in the dog-human dyad. Psychol Res Behav Manag. 2015;8: 71-79.

39. Denenberg S, Landsberg GM. Effects of dog-appeasing pheromones on anxiety and fear in puppies during training and on long-term socialization. $J$ Am Vet Med Assoc. 2008;233:1874-1882.

40. Howell TJ, Bennett PC. Puppy power! Using social cognition research tasks to improve socialization practices for domestic dogs (Canis familiaris). J Vet Behav. 2011;6:195-204.

41. Kubinyi E, Turcsan B, Miklosi A. Dog and owner demographic characteristics and dog personality trait associations. Behav Processes. 2009;81:392-401.

42. Salman MD, New JC, Scarlett JM, Kris P, Ruch-Gallie R, Hetts S. Human and animal factors related to the relinquishment of dogs and cats in 12 selected animal shelters in the United States. J Appl Anim Welf Sci. 1998;3:207-226.
43. New J, John C, Salman MD, Scarlett JM, et al. Moving: characteristics of dogs and cats and those relinquishing them to 12 US animal shelters. J Appl Anim Welf Sci. 1999;2:83-96.

44. Marder A, Duxbury MM. Obtaining a pet: realistic expectations. Vet Clin North Am Small Anim Pract. 2008;38:1145-1162.

45. Kobelt AJ, Hemsworth PH, Barnett JL, Coleman GJ, Butler KL. The behaviour of Labrador retrievers in suburban backyards: the relationships between the backyard environment and dog behaviour. Appl Anim Behav Sci. 2007;106:70-84.

46. Parliament of Victoria. Domestic Animals Amendment (Dangerous Dogs) Act. Melbourne, Australia: State of Victoria; 2010. Available from: http://www.austlii.edu.au/au/legis/vic/bill/daadb2010389/. Accessed March 25, 2015.

47. State of Queensland. Animal Management (Cats and Dogs) Act 2008. Brisbane, Auatralia: State of Queensland; 2013. Available from: https://www.legislation.qld.gov.au/LEGISLTN/CURRENT/A/ AnimalManA08.pdf. Accessed March 25, 2015.

48. Salman MD, Hutchison J, Ruch-Gallie R, et al. Behavioral reasons for relinquishment of dogs and cats to 12 shelters. J Appl Anim Welf Sci. 2000;3(2):93-106.

49. Russell M. Dog home censors its Facebook amid kill rate row. The Age. 2009. Available from: http://www.smh.com.au/national/doghome-censors-its-facebook-amid-kill-rate-row-20091114-ifo 7.html. Accessed March 25, 2015.

50. Diederich C, Giffroy J-M. Behavioural testing in dogs: a review of methodology in search for standardisation. Appl Anim Behav Sci. 2006;97:51-72.

51. Wilsson E, Sundgren P-E. Behaviour test for eight-week old puppies heritabilities of tested behaviour traits and its correspondence to later behaviour. Appl Anim Behav Sci. 1998;58:151-162.

52. Goddard ME, Beilharz RG. Early prediction of adult behaviour in potential guide dogs. Appl Anim Behav Sci. 1986;15:247-260.

53. King T, Marston LC, Bennett PC. Describing the ideal Australian companion dog. Appl Anim Behav Sci. 2009;120:84-93.

54. Buckland EL, Corr SA, Abeyesinghe SM, Wathes CM. Prioritisation of companion dog welfare issues using expert consensus. Anim Welf. 2014;23:39-46.

55. Seksel K. Preventing behavior problems in puppies and kittens. Vet Clin North Am Small Anim Pract. 2008;38:971-982.

56. Animal Health Alliance. Pet ownership in Australia. Australian Capital Territory, Australia; 2013. Available from: http://petsinaustralia.com. au/wp-content/uploads/2014/01/Pet-Ownership-in-Australia-2013Summary-ONLINE-VER.pdf. Accessed March 25, 2015.

57. Craven J. Review of Veterinary Science Education and Registration Requirements. Australian Veterinary Boards Council Inc. 2004. Available from: http://www.ava.com.au/sites/default/files/documents/Other/ Craven\%20ReviewVetSciEducation.pdf. Accessed March 25, 2015.

58. Hynd PI, Hazel SJ. Animal science education in Australia - current situation and future needs. Are current training and education programs appropriate for the animal industry needs over the next 10-15 years. In: Proceedings of the 28th Biennial Conference of the Australian Society of Animal Production, Armidale, Australia, July 11-15, 2010.

59. Howell TJ, Toukhsati S, Conduit R, Bennett P. The Perceptions of Dog Intelligence and Cognitive Skills (PoDIaCS) Survey. J Vet Behav. 2013;8:418-424.

60. Sammet WJ. The first seven weeks: raising well-adjusted puppies. Advice from the Breeder, 2005. Available from: https://www.akc.org/enewsletter/ akc_breeder/2005/december/seven.cfm. Accessed January 29, 2015 .

61. Menteith C, Falconer-Taylor R. The puppy socialisation plan, 2013. Available from; http://www.thepuppyplan.com/. Accessed January 29, 2015. 
Veterinary Medicine: Research and Reports

Dovepress

\section{Publish your work in this journal}

Veterinary Medicine: Research and Reports is an international, Visit http://www.dovepress.com/testimonials.php to read real quotes peer-reviewed, open access journal publishing original research,

case reports, editorials, reviews and commentaries on all areas of

veterinary medicine. The manuscript management system is completely online and includes a very quick and fair peer-review system.

from published authors.

Submit your manuscript here: http://www.dovepress.com/veterinary-medicine-research-and-reports-journal 